\section{Instructions and the magnitude of an illusion: Cognitive factors in the frame of reference* ${ }^{*}$}

\author{
FRANK RFSTLE: \\ Indiana University, Bloomington, Indiana 47401
}

Ss judged the length of a horizontal line having vertical lines at the ends and a vertical line crossing at the middle. As has often been shown, judgments of the horizontal line varied inversely with the length of the vertical segments. One group of $S$ s were told to use the end lines as frame of reference and ignore the center line, and the estimated weights of end and center line were .22 and .02 . The other group were told to ignore the end lines and use the center line as frame of reference. The weights of end and center line for this group were .06 and .22 . It was concluded that the Helson AL equations are valid, but that the weights of parts of the field are partly under voluntary control and are not simply a function of the visual field.

The magnitude of an illusion is greater when $S$ adopts a "whole percciving" attitude than when he uses a "part isolating" attilude (Woodworth \& Schlosberg, 1954). This might be because $\mathrm{S}$ can correct his responses so as to compensate for the illusion without changing the appearance of the stimuli, or it might be because $\mathrm{S}$ can voluntarily change his probabilities of sampling various clements of the ficld, and thereby affect his frame of reference.

Several recent papers (Restle \& Merryman, 1968, 1969; Merryman \& Restle, 1970; Restle, 1970; Restle \& Greeno, 1970) have used a mathematica! model (Helson, 1964) of the frame of reference to explain contrast illusions and the moon illusion. The two equations of this theory are as follows: The judgement, $J_{X}$, of a stimulus of physical valuc, $X$, is given by

$$
\mathrm{J}_{\mathrm{X}}=\mathrm{X} / \mathrm{A}
$$

where $A$ is the average level of the frame of reference. If the stimuti in the field are of magniludes $S_{1}, S_{2}, \cdots, S_{n}$, then $A$ is a weighted geometric mean

$$
A=S_{1}{ }^{\prime \prime}, S_{2}{ }^{\prime \prime}{ }_{2} \cdot . \cdot S_{n}{ }^{\prime \prime} n
$$

The response is taken to be a linear function of $J_{X}$. provided the $S$ uses a rating scale with the usual instructions.

An illusion arises when a given stimulus is observed in two different frames of reference differing with respect to some

* This rexarch was supported by Public Health Service (irant MH 16817. The author thank, Janice Carlson. Who prepared the stimulu materials. and Ans Brown. who wrote the prostrams for analy ws of alata.

tRecuests for reprints should be sent to I rank Restle, Department of Puychology. Indiana l'niversity. Psychology Building, Bloomington. Indiana 47401 stimulus, $S_{\mathbf{T}}$. The magnitude of the illusion depends upon the weight $w_{I}$ given $S_{i}$, the illusion-inducing stimulus.

If the weights of the elements of the frame of reference are determined by the visual array interacting with receptors, then instructions should not affect them, and the effect of instructions must be through response compensation. If, on the contrary, the weights are partly under control of the $S$, then it should be possible to influence them through instructions.

In the present experiment Ss judged a horizontal line of length L having verlical lines of length $F$ at the ends, and cross-line of length S $^{\text {. One group of }} \mathrm{S}$ were told to use $\mathrm{E}$ and ignore $\mathrm{C}$, the other were told to use $\mathrm{C}$ and ignore $\mathrm{E}$. If the weights are under voluntary control, these two groups should show different illusions, each placing more weight on the stimulus 10 which attention was directed.

\section{METHOD}

\section{Subjects}

Twenty-eight students enrolled in introductory psychology courses al Indiana University participated in the experiment to fulfill a course requirement. Ss were run in groups of four, and each such group was assigned to one of 1 wo conditions, resulting in $12 \mathrm{Ss}$ in (iroup 1 and $17 \mathrm{Ss}$ in (iroup 2.

\section{Apparatus and Materials}

Stimuli were slides of white lines on a dark background. Each display consisted of a horizontal line of length $:=8,10$, or $12 \mathrm{~cm}$; vertical lines at the ends of the horizontal line of length $\mathrm{E}=12,14$, or $16 \mathrm{~cm}$; and a vertical line bisecting the horizontal line of length $c=6,8$. or $10 \mathrm{~cm}$. The combinations of L, E. and $C$ produced $3 \times 3 \times 3=27$ displays. The 27 slides werc projected from a Kodak RA-750 random-aceess slide projector onto a screen $3 \mathrm{~m}$ from $S$. The screen was $130 \times 130 \mathrm{~cm}$ and its edges were masked so as to contrast but little with the wall bchind.

\section{Procedure}

On each trial $S$ was shown a slide and he then made a judgment of the length of the horizontal line ( $\mathrm{l}$.) by pressing one of a row of six buttons, the leftmost corresponding to "quite short," the rightmost to "quite long," and the other four to "intermediate lengths."

Group 1 Ss were told to "Try to disregard the center vertical line that crosses right through the test line. Pay altention to the vertical lines at the ends of the test line and use them as a frame of reference to help you in your judgments." The instructions were given verbatim as above and then paraphrased again after Ss were told about the responses. Group $2 \mathrm{Ss}$ were told to "Try to disregard the vertical lines at the ends of the test line. Pay attention to the center vertical line that crosses right through the test line and use it as a frame of reference to help you in your judgments."

When a stimulus was presented, an amber light on $S$ 's response panel was lit. That amber light went off when the response was made. Whenever all $S$ responded, the slide went off and a new slide was scarched for. The maximum time allowed was $6 \mathrm{sec}$ to respond, and there was a 5 -sec wait between slides. The 27 slides were shown seven times in seven random permutations to each group of Ss. and responses $t 0$ the last five trials are reported. All programming of stimuli, presentation of slides, and data collection were done by an IBM 1800 on-line computer.

\section{RESULTS}

The first step of analysis is to reduce the data to parameter estimates. Fis. 1 and 2 imply that

$$
J_{1}=L / C^{C} E^{C} K^{1}
$$

where $c$ and $e$ are the weights of the cross line and end lines, respectively, and $K$ is the unknown resultant of all constan or random factors in the experiment. Taking logarithms,

$\log J_{1}$

$$
\begin{aligned}
& =\log \mathrm{L} \quad c \log \mathrm{C}-\mathrm{c} \log \mathrm{L}:(1-\mathrm{c}-\mathrm{e}) \log \mathrm{K} \\
& =\log \mathrm{L}+\text { constant. }
\end{aligned}
$$

II the raw responses are taken as the judgments, calling the leftmost button 1 , ctc., then Eq. 3 is not satisfied since the slope of $\log J_{1}$ vs $\log L$, is not unity. For each $S$, a constant $Z$ was found so that his responsc, $R_{1}$, satisficd the equation 


$$
\log \left(R_{L}+Z\right)=\log J_{L}=\log L+\text { constant }
$$

with $\mathrm{J}_{\mathrm{L}}$ defined as above. The value of $\mathrm{Z}$ may be interpreted as the "zero point" of the scale used by S. Determination of such a zero point reduces individual differences considerably and provides a close agreement between model and data for every $S$.

A standard linear multiple regression of $\log J_{L}$ on $\log C$ and $\log E$ was then performed for each $\mathrm{S}$, and the parameters $\mathrm{c}$ and e estimated for each $\mathrm{S}$.

The main experimental hypothesis was that Group I Ss, instructed to use E and ignore $C$, would yield larger values of $e$ than of $c$. The mean values were .221 and .056 , respectively. Group $2 \mathrm{Ss}$ were instructed to ignore $E$ and use $C$, hence should yield smaller values of $\mathrm{e}$ than of $\mathrm{c}$. Their mean values were .024 and .219 , respectively. The difference between groups in e-c was statistically significant $[\mathrm{t}(27)=2.96, \mathrm{p}<.01]$.

\section{DISCUSSION}

Ss can voluntarily change the relative weights of various stimuli in their frame of reference if instructed to do so. The resulting difference in weight leads to different measured illusions in the visual field.

This result supports the position taken by the author (Restle, 1970) with respect to individual differences in the magnitude of the moon illusion, that various Ss might use different frames of reference (the magnitude of objects on the horizon, the total extent of the visual field, or their own noses), employing different strategies, and for that reason make consistently different judgments.

It might be objected that the present results are contaminated, because the visual fixation point was not controlled, and no direct observations of the Ss' ocular orientations were made. However, our sampling theory of the frame of reference holds that perceiving involves active search, and that the frame of reference depends upon where the $S$ centers his viewpoint. In this experiment, we have measured the judgmental consequences of instructions. The final result is what is of interest here, though it would be interesting to learn the results of studies of visual fixation in this task. If fixation were controlled, then our effect might be sharply attenuated, even though the effect is large under normal viewing conditions. If it were found that ocular orientation depends on instructions, in this task, then it would still be necessary to show that those visual fixations produced the observed difference in judgment.

The notion of perceptual sampling employed in this paper is similar to Piaget's (1961) except that Piaget says that the part of the field centered by the $S$ is thereby made larger, whereas in the present model, the part of the field centered is merely thereby made part of the frame of reference. Since Ss were not judging the parts of the field emphasized by instructions, Piaget's concept would not predict any differences in performance between the groups of the present experiment.

\section{REFERENCES}

HELSON, H. Adaptation-level theory. New York: Harper \& Row, 1964.

MERRYMAN, C. T., \& RESTLE, F. Perceptual displacement of a test mark toward the larger of two visual objects. Journal of Experimental Psychology, 1970, in press.

PIAGET, J. Les mechanismis perceptifs. Paris: Presses Universitaires de France, 1961.

RESTLE, F. Moon illusion explained on the basis of relative size. Science, 1970, 167, 1092-1096.

RESTLE, F., \& GREENO, J. G. Introduction to mathematical psychology. Reading, Mass: Addison-Wesley, 1970.

RESTLE, I., \& MERRYMAN, C. T. An adaptation-level theory account of a relative-size illusion. Psychonomic Science, $1968,12,229-230$.

RESTLE. F., \& MERRYMAN, C. T. Distance and an illusion of length of line. Journal of lexperimental Psychology, 1969, 81, 297-302. WOODWORTH, R. S., \& SCHLOSBERG, H. Experimental psychology. New York: Holt Rinehart \& Winston, 1954.

(Accepted for publication May 15, 1970.) 